
Pathophysiology of Haemostasis and Thrombosis

Received: December 29, 2001

Accepted in revised form: February 16, 2002

\title{
Effect of Low-Molecular-Weight Heparin on Potassium Homeostasis
}

\author{
Majdi M. Abdel-Raheem ${ }^{a}$ Anil Pottia,b Sherine Tadrosa Vijay Koka ${ }^{a}$ \\ David Hanekom ${ }^{a}$ Genise Fraiman ${ }^{b}$ Byron D. Danielson ${ }^{c}$ \\ aDepartment of Medicine, University of North Dakota School of Medicine, bepartment of Medicine, \\ Division of Hematology, Veterans' Affairs Medical Center, and 'Department of Medicine, Division of Nephrology, \\ Veterans' Affairs Medical Center, Fargo, N. Dak., USA
}

\section{Key Words}

Transtubular potassium gradient.

Low-molecular-weight heparin - Adverse effect .

Hyperkalemia

\begin{abstract}
Background: Low-molecular-weight heparins (LMWHs) are being preferred to unfractionated heparin (UFH) because of their superior convenience and a comparable or slightly better toxicity profile. Whether LMWH has an inhibitory effect on aldosterone that causes hyperkalemia is yet uncertain. Methods: Twenty-eight patients (all male; mean age: 70 years, range 52-87 years) placed on LMWH therapy ( $40 \mathrm{mg}$ subcutaneously every $12 \mathrm{~h}$ ) for deep venous thrombosis prophylaxis after an operation were included in the study. Transtubular potassium concentration gradient (TTKG) was calculated 1 day prior to LMWH therapy and again after 4 days of treatment. Of the 28 patients enrolled in the study, we were able to calculate the TTKG in only 19 patients: 9 had a urinary osmolarity (either before or after LMWH therapy) less than the serum osmolarity, making the TTKG calculation unreliable. The Wilcoxon signed-rank test was used to analyze differences in the median serum potassium levels and TTKG before and after LMWH therapy. Results: All patients had adequate renal function (creatinine
\end{abstract}

\section{KARGER}

Fax +41613061234

E-Mail karger@karger.ch

www. karger.com

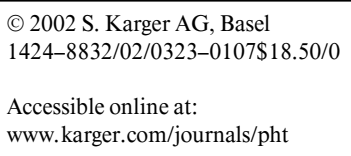

clearance $>90 \mathrm{ml} / \mathrm{min}$ ). Mean ( $\pm \mathrm{SD}$ ) serum potassium concentration before LMWH was $4.25( \pm 0.40) \mathrm{mmol} / \mathrm{dl}$. It increased to $4.35( \pm 0.41) \mathrm{mmol} / \mathrm{dl}$ after initiating LMWH therapy $(p=0.09)$. Similarly, the mean ( \pm SD) TKKG calculated was $5.52( \pm 2.33)$ before and 5.97 ( \pm 3.06) after 4 days of LMWH $(p=0.54)$. Conclusions: Unlike UFH, LMWH (Lovenox ${ }^{\circledR}$ ) in doses used for postoperative prophylaxis against deep venous thrombosis does not seem to have a significant effect on potassium homeostasis.

Copyright $\odot 2002$ S. Karger AG, Base

\section{Introduction}

Unfractionated heparin (UFH) has been the mainstay of anticoagulation therapy for more than 50 years. Major side effects of UFH therapy include an increased risk of bleeding, heparin-induced thrombocytopenia, thrombosis, osteoporosis and alopecia [1]. Potassium homeostasis is regulated by the kidney and controlled by the reninangiotensin-aldosterone system. A known but often overlooked complication of UFH therapy is hyperkalemia (incidence of $8 \%$ ), attributable to aldosterone suppression [2].

Recently, the increased usage of low-molecular-weight heparins (LMWH) has led to infrequent laboratory moni-

Anil Potti, MD

Department of Internal Medicine, University of North Dakota School of Medicine 1919 N Elm Street, Fargo, ND 58102 (USA)

Tel. +1 701293 4131, Fax +1 701293 4145, E-Mail anilpotti@meritcare.com 
toring in the clinic and hospital setting. LMWHs are being preferred due to their superior convenience and efficacy while having a comparable or slightly better toxicity profile when compared with unfractionated heparins. Whether LMWH has an inhibitory effect on aldosterone that causes hyperkalemia is yet uncertain.

Urinary potassium excretion is calculable as potassium concentration in the lumen of the cortical collecting duct (CCD) times the urine flow rate [3]. Although a random urinary potassium concentration is easy to calculate, it may be misleading as water reabsorption in the medullary collecting duct (MCD) will influence the potassium concentration in the final urine. The other major disadvantage of a random urine sample is that it may not be a representative specimen [3]. A novel clinical approach in evaluating urinary potassium excretion is determining the transtubular potassium concentration gradient (TTKG).

The TTKG is an indirect, semiquantitative index that reflects the driving force of potassium secretion in the cortical distal nephron. It is considered an easy and sensitive method for the evaluation of mineralocorticoid action in the distal and collecting tubules $[4,5]$. Once urinary potassium concentrations have been adjusted for medullary water reabsorption, TTKG describes the ratio of potassium concentrations in the urine to the serum potassium concentration $\left[\mathrm{K}^{+}\right]$. Hence TTKG is calculated using the formula: $\left[\mathrm{K}^{+}\right]$urine/(urine/plasma osmolarity)/ $\left[\mathrm{K}^{+}\right]$plasma. We conducted a prospective study to determine the effect of LMWH on the renal handling of potassium.

\section{Materials and Methods}

This study was conducted between 1999 and 2001 at the Veterans' Administration Medical Center in Fargo, N. Dak., USA. Twenty-eight patients admitted for elective total hip or knee arthroplasty and placed on LMWH therapy (Lovenox ${ }^{\circledR}$ ) for deep venous thrombosis prophylaxis after the operation were included in the study. All subjects were placed on LMWH $40 \mathrm{mg}$ subcutaneously every $12 \mathrm{~h}$ for a duration of at least 4 days. We did not include patients with clinical conditions that may interfere with potassium homeostasis and act as confounding variables, e.g. history of diabetes mellitus, patients on angiotensin-converting enzyme inhibitors or angiotensin receptor blocker therapy, as well as patients on potassium supplements, nonsteroidal anti-inflammatory drugs, and diuretics.

All patients were males. Mean age was 70 years (range 52-87 years). All patients had adequate renal function (creatinine clearance $>90 \mathrm{ml} / \mathrm{min}$ ). Baseline serum potassium, creatinine, osmolarity, urinary sodium and potassium concentrations and urinary osmolarity were obtained from all patients before the initiation of LMWH therapy. All laboratory parameters were evaluated again after 4 days of LMWH therapy.
TTKG was calculated 1 day prior to LMWH therapy and again 4 days after LMWH therapy had been initiated. The calculation of TTKG assumes that water is normally reabsorbed in the collecting duct, resulting in an appropriate urine osmolarity. Such an assumption is true only in the presence of antidiuretic hormone (ADH) action. Therefore, to meet these criteria for the TTKG to be useful in the evaluation of potassium secretion, urine osmolarity must be equal or higher than plasma osmolarity. If urine osmolarity is lower than serum osmolarity, the calculation of TTKG would be unreliable since the amount of water reabsorbed in the collecting duct is unknown [3]. Thus only 19 of the 28 patients included in our study were eligible for TTKG calculations, since 9 patients had a urinary osmolarity (either before or after LMWH therapy) that was lower than the serum osmolarity, making the TTKG calculation unreliable [3]. Statistical analysis was done using SPSS $-10^{\circledR}$ for Windows ${ }^{\circledR}$. As the serum potassium levels and the TTKG values were not normally distributed, we used a nonparametric test to compare the results. The Wilcoxon signed-rank test was used to analyze differences in the median serum potassium levels and TTKG before and after LMWH therapy.

\section{Results}

\section{Effect of LMWH on Serum Potassium Concentration}

Serum potassium concentrations before and after LMWH were obtained and analyzed in the 28 patients who entered the study. Mean ( \pm SD) serum potassium concentration before LMWH was $4.25( \pm 0.40) \mathrm{mmol} / \mathrm{dl}$. It increased to $4.35( \pm 0.41) \mathrm{mmol} / \mathrm{dl}$ after initiating LMWH therapy (table 1). Although the mean serum potassium levels increased by $0.1 \mathrm{mmol} / \mathrm{dl}$, this was not statistically significant $(\mathrm{p}=0.09)$.

\section{Effect of LMWH on TTKG}

Only 19 patients were candidates for a reliable TTKG calculation (table 1). Mean ( \pm SD) TTKG was 5.52 $( \pm 2.33)$ before LMWH therapy and $5.97( \pm 3.06)$ and after 4 days. The mean increase in TTKG $(0.45)$ was not statistically significant $(\mathrm{p}=0.54)$.

\section{Discussion}

Hyperkalemia is an interesting, albeit less considered adverse effect of UFH. Clinical reports suggest that heparin-induced hyperkalemia might occur in approximately $7-8 \%$ of patients treated with UFH [1]. It is a reversible sideeffect and is independent of either anticoagulant effect or route of administration [2].

Heparin exerts a predictable, potent, and reversible inhibitory effect on aldosterone production. Aldosterone suppression occurs within a few days of initiation of ther- 
Table 1. Serum potassium levels and TTKG before (pre- $\left.\mathrm{K}^{+}\right)$and after 4 days (post- $\mathrm{K}^{+}$) of LMWH therapy

\begin{tabular}{|c|c|c|c|c|}
\hline \multirow[t]{2}{*}{ Case } & \multicolumn{2}{|c|}{$\begin{array}{l}\text { Serum potassium levels }{ }^{1} \\
\mathrm{mmol} / \mathrm{dl}\end{array}$} & \multicolumn{2}{|l|}{$\mathrm{TTKG}^{2}$} \\
\hline & pre-K ${ }^{+}$ & post-K ${ }^{+}$ & pre-K ${ }^{+}$ & post-K ${ }^{+}$ \\
\hline 1 & 4.3 & 4.7 & 3.93 & 6.26 \\
\hline 2 & 4.4 & 4.6 & 6.92 & 7.65 \\
\hline 3 & 3.8 & 4.2 & 5.24 & 6.32 \\
\hline 4 & 4.3 & 4.4 & - & - \\
\hline 5 & 3.9 & 3.7 & 3.15 & 1.77 \\
\hline 6 & 4 & 3.7 & 2.77 & 10.5 \\
\hline 7 & 3.5 & 3.4 & 10.54 & 6.95 \\
\hline 8 & 4.6 & 4.6 & - & - \\
\hline 9 & 4.1 & 4.1 & 2.79 & 5.3 \\
\hline 10 & 3.8 & 4.5 & 6.99 & 5.7 \\
\hline 11 & 4.7 & 4.6 & 7.21 & 4.0 \\
\hline 12 & 4.5 & 4.7 & 4.37 & 4.11 \\
\hline 13 & 4.7 & 4.8 & - & - \\
\hline 14 & 3.9 & 4.2 & - & - \\
\hline 15 & 4.2 & 4.2 & 9.6 & 14.97 \\
\hline 16 & 4.3 & 3.9 & - & - \\
\hline 17 & 4.6 & 5.2 & 5.678 & 5.12 \\
\hline 18 & 4.6 & 4.4 & 3.95 & 4.48 \\
\hline 19 & 3.5 & 4.2 & - & - \\
\hline 20 & 4.3 & 4.4 & 7.36 & 1.87 \\
\hline 21 & 4.1 & 4.0 & 5.61 & 7.12 \\
\hline 22 & 3.9 & 4.1 & - & - \\
\hline 23 & 5.0 & 4.9 & 3.78 & 5.97 \\
\hline 24 & 4.4 & 4.7 & - & - \\
\hline 25 & 4.4 & 4.4 & 4.12 & 4.02 \\
\hline 26 & 3.8 & 4.1 & 6.80 & 6.21 \\
\hline 27 & 4.9 & 4.8 & 2.69 & 3.23 \\
\hline 28 & 4.6 & 4.8 & - & - \\
\hline Mean \pm SD & $4.25 \pm 0.4$ & $4.35 \pm 0.41$ & $5.52 \pm 2.33$ & $5.97 \pm 3.06$ \\
\hline $\mathrm{p}$ value & & 0.09 & & 0.54 \\
\hline
\end{tabular}

1 Serum potassium levels were determined in 28 patients. TTKG was evaluated in 19 patients.

apy. This effect is specific to the zona glomerulosa; other corticosteroids are not suppressed. Heparin probably interferes with adrenal aldosterone production through several different mechanisms, the most important appears to involve reduction in both the number and affinity of the angiotensin II receptors in the zona glomerulosa [2].

Although previous reports have shown LMWH therapy to increase serum potassium concentration [6, 7], others failed to show similar results [8]. Conflicting data regarding the effect of LMWH on aldosterone secretion exist as well [7, 9]. However, unlike our study, most of the previous studies were retrospective trials. In comparison toUFH, if LMWH is to have any effect on aldosterone secretion, it is reasonable to postulate that this will translate into an increase in serum potassium concentration and a decrease in urinary potassium excretion. Comparing the differences in serum potassium levels before and after LMWH therapy should reveal such trends, if there are any. Also, comparing the TTKG before and after LMWH therapy would outline any effect LMWH might have on the renal handling of potassium excretion. Our prospective study was designed to investigate such effects.

Calculation of TTKG is based on the assumption that a small proportion of osmoles is reabsorbed between the end of the terminal CCD and the final urine. This assumption is invalid when there is a very low tubular flow rate and a higher proportion of sodium and chloride versus urea reabsorption in the MCD (e.g., extracellular fluid volume depletion together with a low protein intake). This will decrease the rise in osmolarity and the calculated TTKG will be overestimated accordingly. Reduced sodium delivery to the cortical nephron can also limit the secretion of potassium [3]. Hence the use of this index is restricted to situations where the urine is not hypotonic and distal nephron sodium delivery is not limiting potassium secretion (greater than $25 \mathrm{mM}$, twice the sodium concentration required for maximum potassium transport at this nephron site) [4].

Our findings showed no clinically or statistically significant change in serum potassium concentrations following LMWH therapy $(\mathrm{p}=0.09)$ (table 1). Also, a demonstrable effect of LMWH therapy on the renal potassium handling (lack of significant changes in the TTKG before and after Lovenox therapy, $(p=0.54)$ was not evident.

Generally, routine monitoring of serum potassium at appropriate intervals is recommended in patients receiving heparin for more than 3 days [2]. However, due to the yet undetermined effect of LMWH on potassium homeostasis, it has not been recommended to monitor serum potassium in patients receiving such therapy. Although our prospective study was limited by the small number of patients enrolled, we did not demonstrate a statistically or clinically significant effect of LMWH on potassium homeostasis to warrant routine monitoring of serum potassium levels in patients receiving LMWH therapy. Another possible concern that is not addressed by our study is the possibility of a dose-related effect of LMWH therapy on potassium handling, since all our patients received a standard prophylactic dose of Lovenox therapy, which is usually lower than the recommended dose for the treatment of venous thromboembolic conditions. It is also important to note that the LMWH used in our study was 
Lovenox, and since the different LMWHs have individual differences, the results of our study cannot be generalized to all LMWHs.

Unlike UFH, LMWH (Lovenox) in doses used for post-operative prophylaxis against deep venous thrombosis does not seem to have a significant effect on potassium homeostasis. Our study failed to show a clinically signifi- cant effect of LMWH on serum potassium concentrations and urinary potassium excretion, thus providing further evidence of a beneficial sideeffect profile compared with UFH therapy. Due to the widespread use of LMWHs, larger trials assessing individual agents are needed to define the impact of LMWHs on renal potassium handling.

\section{References}

1 Hirsh J, Raschke R, Warkentin TE, Dalen JE, Deykin D, Poller L: Heparin: Mechanism of action, pharmacokinetics, dosing considerations, monitoring, efficacy, and safety. Chest 1995; 108 (suppl):258S-275S.

2 Oster JR, Singer I, Fishman LM: Heparininduced aldosterone suppression and hyperkalemia. Am J Med 1995;98:575-586.

3 Halperin ML, Goldstein MB: Fluid, Electrolyte, and Acid-Base Physiology: A ProblemBased Approach, ed 3.Philadelphia, Saunders, 1998.
4 West ML, Marsden PA, Richardson RM, Zettle RM, Halperin ML: New clinical approach to evaluate disorders of potassium excretion. Miner Electrolyte Metab 1986;12:234-238.

5 DuBose TD Jr: Hyperkalemic hyperchloremic metabolic acidosis: Pathophysiologic insights. Kidney Int 1997;51:591-602.

6 Canova CR, Fischler MP, Reinhart WH: Effect of low-molecular-weight heparin on serum potassium. Lancet 1997;349:1447-1448.
7 Levesque H, Verdier S, Cailleux N, et al: Low molecular weight heparins and hypoaldosteronism. BMJ 1990;300:1437-1438.

8 Wong KS, Kay R: Low-molecular-weight heparin and serum potassium. Lancet 1997;350: 664.

9 Marcelli JM, Lalau JD, Abourachid H, Quiret JC, Quichaud J: Unlike heparin, low-molecular weight heparin does not suppress aldosterone production. Horm Metab Res 1989;21:402. 